\title{
ALTERACCÕES LABORATORIAIS E IMAGINOLÓGICAS ASSOCIADAS AO QUADRO DE DESNUTRIÇÃO SECUNDÁRIA À INSUFICIÊNCIA PANCREÁTICA EXÓCRINA EM CÃES: RELATO DE DOIS CASOS
}

Mariana Yukari Hayasaki Porsani1 ${ }^{1}$ Monique Paludetti², Imara Guimarães Lima3 ${ }^{3}$ Camila Santos Pereira ${ }^{4}$, Antonio Carlos Cunha Lacreta Junior ${ }^{5}$, Raimundo Vicente de Sousa ${ }^{6}$

${ }^{1}$ Médica Veterinária, Mestre, Universidade Federal de Lavras (UFLA) - Lavras, Brasil. E-mail: mariporsani@hotmail.com.

${ }^{2}$ Graduanda em Medicina Veterinária, Universidade Federal de Lavras (UFLA) Lavras, Brasil.

3Médica Veterinária, Mestranda em Ciências Veterinárias, Universidade Federal de Lavras (UFLA) - Lavras, Brasil.

${ }^{4}$ Médica Veterinária, Mestranda em Ciências Veterinárias, Universidade Federal de Lavras (UFLA) - Lavras, Brasil.

${ }^{5}$ DSc. Docente do Departamento de Medicina Veterinária, Universidade Federal de Lavras (UFLA) - Lavras, Brasil.

${ }^{6}$ DSc. Docente do Departamento de Medicina Veterinária, Universidade Federal de Lavras (UFLA) - Lavras, Brasil.

Recebido em: 08/09/2015 - Aprovado em: 14/11/2015 - Publicado em: 01/12/2015 DOI: http://dx.doi.org/10.18677/Enciclopedia_Biosfera_2015_072

\section{RESUMO}

A insuficiência pancreática exócrina (IPE) ocorre por deficiência na secreção de enzimas digestivas, levando à má digestão e absorção de nutrientes resultando em desnutrição. O diagnóstico é um desafio, pois se baseia no histórico, alterações clínicas e laboratoriais. Os resultados dos exames complementares destes animais podem ser inespecíficos estando normalmente correlacionados com um quadro de desnutrição. Relata-se dois casos de cães com IPE nos quais se observa diversas alterações hematológicas e bioquímicas, tais como aumento da atividade das enzimas hepáticas, hipoproteinemia e anemia, além de alterações no exame ultrassonográfico, sugestivas de esteatose hepática e pancreatite associados ao quadro de desnutrição secundária à IPE.

PALAVRAS-CHAVE: esteatose, hipoproteinemia, má digestão, pâncreas, perda muscular. 


\title{
LABORATORY AND IMAGINOLOGICAL CHANGES ASSOCIATED WITH MALNUTRITION SECONDARY TO EXOCRINE PANCREATIC INSUFFICIENCY IN DOGS: TWO CASES REPORT
}

\begin{abstract}
The exocrine pancreatic insufficiency (EPI) is a deficiency in the secretion of digestive enzymes, leading to poor digestion and absorption of nutrients resulting in malnutrition. The diagnosis is challenging because it is based on history, clinical and laboratory changes. The results of laboratory tests of these animals can be nonspecific and is usually correlated with a malnourished condition. It is reported the case of two dogs with EPI which was observed hematological and biochemical changes such as increase in liver enzyme activity, hypoproteinemia and anemia, as well as changes on ultrasound examination suggestive of hepatic steatosis and pancreatitis associated with malnutrition frame secondary to IPE.
\end{abstract}

KEYWORDS: steatosis, hypoproteinemia, poor digestion, pancreas, muscle loss.

\section{INTRODUÇÃO}

O pâncreas é uma glândula mista, composto por uma porção endócrina e outra exócrina (MARCATO, 2010). A porção endócrina é responsável pela secreção de hormônios e a porção exócrina pela liberação de enzimas que promovem a digestão dos alimentos para posterior absorção dos nutrientes (MORGAN \& MOORE, 2009).

A secreção insuficiente das enzimas digestivas leva a sinais clínicos de má digestão e absorção, como polifagia, alteração de defecação e emagrecimento progressivo, sinais estes que caracterizam a insuficiência pancreática exócrina (IPE) (BRENNER et al., 2009; GERMAN, 2012; WESTERMARCK \& WIBERG, 2012). Entre as causas mais comuns estão a atrofia acinar pancreática, aplasia ou hipoplasia pancreática (BRENNER et al., 2009). Entretanto, esta enfermidade também pode ser estabelecida em quadros de pancreatite crônica, neoplasias pancreáticas, após cirurgia abdominal e em infecção por Eurytrema procyonis (BRENNER et al., 2009; STEINER et al., 2012). A IPE não possui predisposição racial, embora seja comum em cães das raças Pastor Alemão, Collies (WESTERMARCK et al., 2010), Cavalier King Charles, Cocker Spaniels e West Highland White Terriers (GERMAN, 2012; WESTERMARCK \& WIBERG, 2012).

Alterações na defecação são relatadas na IPE, tais como aumento do volume e frequência (BRENNER et al., 2009). Pode ser observada alteração na coloração das fezes, sendo esta amarelada ou acinzentada com presença de esteatorréia (GERMAN, 2012; WESTERMARCK \& WIBERG, 2012). Perda acentuada de peso (NELSON \& COUTO, 2009; STEINER et al., 2012), assim como perda de pelame, também são vistos em animais acometidos por esta enfermidade (STEINER et al., 2012). Complicações graves como diabetes, doença de Bowen e colangites podem estar associadas à evolução da doença (STEINER et al., 2012).

O diagnóstico clínico da IPE é baseado no histórico e nas manifestações clínicas (WESTERMARCK et al, 2010; WESTERMARCK \& WIBERG, 2012). Teste de atividade proteolítica fecal, determinação da imunorreatividade semelhante à tripsina sérica e da lipase pancreática, assim como a determinação da elastase pancreática fecal são empregados na rotina clínica para auxiliar no diagnóstico da IPE (MORGAN \& MOORE, 2009; WESTERMARCK \& WIBERG, 2012). Os exames de imagem e laboratoriais (hemograma e testes bioquímicos) podem também 
auxiliar no diagnóstico, porém quando realizados isoladamente não concluem o diagnóstico (WESTERMARCK \& WIBERG, 2012).

A redução da cobalamina sérica (Vitamina B12) pode ser vista em pacientes com IPE devido à redução da liberação de fatores intrínsecos pelo pâncreas exócrino que auxiliam na absorção desta vitamina (WESTERMARCK \& WIBERG, 2012).

Exames laboratoriais apresentam alterações inespecíficas, podendo ser realizada a confirmação do diagnóstico através do exame histopatológico do pâncreas (WESTERMARCK \& WIBERG, 2012). Quadros de caquexia com grande perda de peso e massa muscular são associados à desnutrição causada pela IPE (WILLIAMS, 2008), sendo possível visibilizar discretas alterações hematológicas, como baixas concentrações de albumina e globulinas, além de linfopenia, neutrofilia e eosinofilia (STEINER et al., 2012).

Nestes quadros de desnutrição nos quais os índices de massa e gordura corporal são reduzidos ocorre a perda fisiológica da homeostasia. Sendo o fígado, órgão central do metabolismo, quase sempre afetado (COUTO et al., 2008), consequentemente visualiza-se um aumento da atividade das enzimas hepáticas FA, ALT e AST possivelmente decorrente da morte celular de hepatócitos (COUTO et al., 2008; NAGATA et al., 2015).

A perda energético-proteica leva à deterioração das funções hepáticas com aumento de ALT, AST e FA (CHOWDHURY et al., 2007; COUTO et al., 2008; NAGATA et al., 2015). Estudo realizado por NAGATA et al. (2015) em pacientes humanos com anorexia nervosa demonstrou que a perda de massa muscular e gordura corporal promoveu o aumento da ALT e AST devido a hipóxia hepática e a diminuição da pressão portal. Em estudo com crianças desnutridas, realizado por CHOWDHURY et al. (2007), também foi observado valores acima da normalidade para estas enzimas hepáticas, sendo tal fato correlacionado com a desnutrição.

Em casos de pancreatite canina a ultrassonografia abdominal apresenta grande importância no diagnóstico, com sensibilidade de $68 \%$ em cães com pancreatite grave. Na pancreatite aguda, há aumento de tamanho pancreático, o qual pode apresentar irregular e hipoecogênico, com dilatação de ductos biliares e região peripancreática hiperecogênica. Na pancreatite crônica, há diminuição de tamanho pancreático, o qual pode apresentar parênquima com ecogenicidade mista, ecotextura nodular, sombra acústica devido à mineralização e cicatrização, além de dilatação de dutos pancreáticos (HECHT \& HENRY, 2007).

Objetivou-se com este estudo relatar as alterações laboratoriais e imaginológicas de dois caninos com insuficiência pancreática exócrina.

\section{RELATO DE CASO}

Foram atendidos dois cães no município de Lavras - Minas Gerais, Brasil. O primeiro caso se trata de um cão, da raça Cocker Spaniel, fêmea, castrada, com 12 anos, pesando $7,8 \mathrm{~kg}$, escore corporal 4 de acordo com a escala de 9 pontos descrita por LAFLAMME (1997) (Figuras 1 e 2). O proprietário relatava emagrecimento progressivo, polifagia, perda do pelame, prostração, alteração nas fezes com aumento na frequência e volume fecais, além de coloração amarelada com presença de esteatorréia. Em dois meses o animal perdeu aproximadamente $2,5 \mathrm{~kg}$ do peso corporal (Figura 2). Ao exame físico notou-se mucosas ictéricas, grandes áreas de hipotricose e ressecamento de pelame (Figura 1), além de sinais de subnutrição por meio da facilidade de palpação e visualização das costelas. Foram realizados exames complementares por meio da venopunção da veia jugular 
externa, sendo colhidos 2,0mL de sangue, com auxílio de agulhas de $25 \times 7 \mathrm{~mm}$ e envasado em tubos adequados: $1 \mathrm{~mL}$ em um tubo contendo o anticoagulante ácido eatilenodiaminotetracético dipotássico (EDTA) a 10\%, na proporção de $1 \mathrm{mg} / \mathrm{mL}$ de sangue, conforme recomendações de Rosenfeld (1955), e $1 \mathrm{ml}$ de sangue em tudo sem anticoagulante. O hemograma foi realizado pelo Analisador Hematológico (Sysmex® modelo poch - 100iv Diff), no qual evidenciou-se anemia normocítica normocrômica acentuada e leucocitose com desvio à esquerda (Tabela 1).

Para bioquímica sérica o sangue foi centrifugado e posteriormente o plasma analisado. A uréia foi determinada pelo método enzimático-colorimétrico, por reação com urease, sendo realizada a leitura em comprimento de onda de $600 \mathrm{~nm}$. A creatinina sérica foi determinada por método colorimétrico, por reação com picrato alcalino, a leitura foi feita em comprimento de onda de $520 \mathrm{~nm}$. Não foram evidenciadas alterações nestas mensurações (Tabela 1). A alanina aminotransferase (ALT) foi determinada pelo método Frankel Reitman e a fosfatase alcalina (FA) pelo método Roy modificado, realizando-se a leitura em espectrofotômetro com comprimento de onda de $505 \mathrm{~nm}$ para a ALT e $590 \mathrm{~nm}$ para ALP (Labetest $\left.{ }^{\circledR}\right)$, notando-se aumento de ambas (Tabela 1). Para as bilirrubinas totais, bilirrubina direta e bilirrubina indireta utilizou-se o aparelho de bioquímica automatizado (Ciba Express 550®) e reativos comerciais (Labtest ${ }^{\circledR}$ ), sendo todos os resultados acima dos valores de referência (Tabela 1). As proteínas séricas totais foram determinadas pelo método colorimétrico, por reação com biureto e globulina pelo método de verde bromocresol sendo ambas submetidas a leitura em comprimento de onda de $550 \mathrm{~nm}$. No qual verificou-se hipoproteinemia (Tabela 1). A glicemia foi mensurada com glicosímetro da marca Glucotrend (Boehringer Mannheim) e apresentou-se dentro da normalidade.

A mensuração da atividade proteolítica fecal foi realizada com três amostras: uma sem fezes (controle negativo), outra com 2 gramas de fezes de cão sadio (controle positivo) e outra com 2 gramas de fezes do animal. Sendo feita solução com $9 \mathrm{~mL}$ de água destilada e $1 \mathrm{~mL}$ de solução de bicarbonato, as fezes e uma fita de filme radiográfico. As amostras foram colocadas em estufa a $37^{\circ}$ Celcius por duas horas. Esta mensuração foi realizada em dois momentos e apresentou resultados controversos.

O exame ultrassonográfico mostrou aumento da ecogenicidade e artefato de impedância acústica em região hepática. Desse modo optou-se pela biópsia do fígado guiada por ultrassonografia. Para realização deste procedimento foi necessário mensurar o tempo de protrombina e tempo de tromboplastina parcial para evitar hemorragia durante o procedimento. Para essa análise foi colhido por venopunção cefálica $2 \mathrm{ml}$ de sangue e acondicionadas em tubos de citrato de sódio a $3,8 \%$, sendo o plasma separado por centrifugação e as determinações realizadas posteriormente pelo método semi automático. Pela biopsia hepática foi encontrado esteatose acentuada, fibrose e retenção de pigmento biliar.

Foi prescrito ao animal uma colher de sopa de pancreatina junto às refeições, sendo a ração hipoalergênica a dieta de escolha. $O$ animal apresentou melhora rápida com reestabelecimento da condição corporal e atitude. 


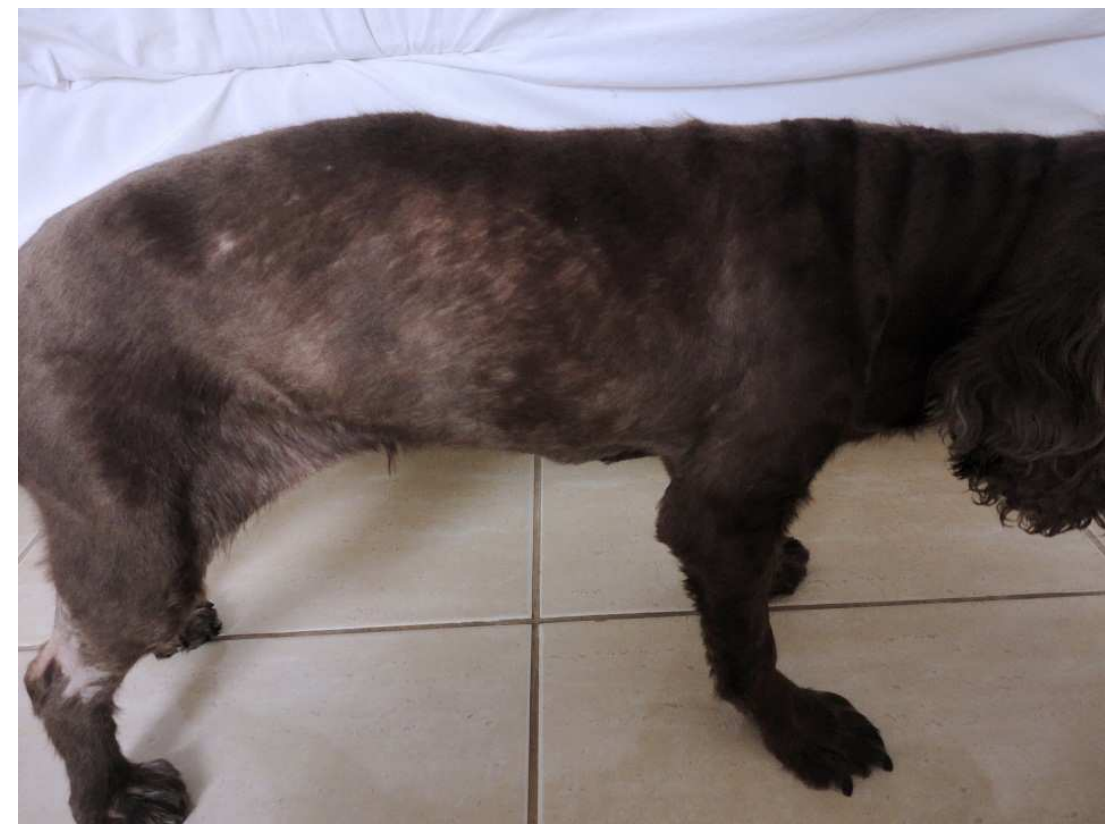

FIGURA 1: Cão, fêmea, Cocker Spaniel, Escore corporal $4 / 9$, hipotricose e ressecamento de pelame. Fonte: Arquivo pessoal.

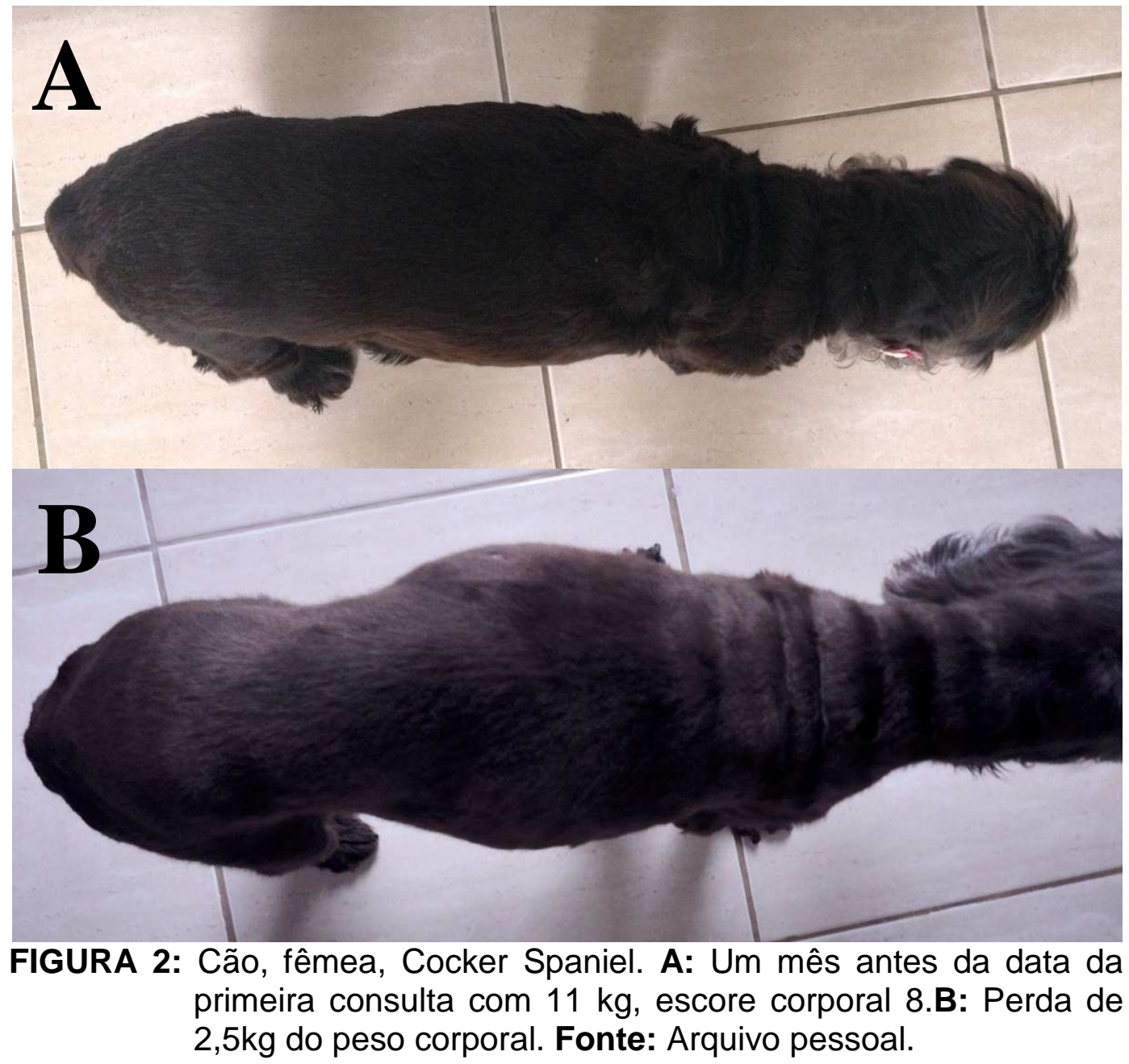


O segundo caso refere-se a um canino da raça Border Collie, macho, não castrado, com 1 ano, pesando $11 \mathrm{~kg}$, escore corporal 1/9 (LAFLAMME, 1997) (Figura 3), caracterizando grau avançado de desnutrição. $O$ proprietário relatou emagrecimento progressivo com aumento da frequência de defecação (em torno de oito vezes/dia) contendo presença de alimentos não digeridos nas fezes e vômitos esporádicos. Ao exame físico notou-se mucosas perláceas, baixa pressão arterial sistólica $(95 \times 90 \times 90 \mathrm{mmHg})$ e prostração acentuada. Por meio da venopunção da veia jugular externa, foram colhidos $2,0 \mathrm{~mL}$ de sangue, com auxílio de agulhas de 25 $X 7 \mathrm{~mm}$ e envasados em tubos adequados contendo o anticoagulante EDTA. Realizados exames laboratoriais (Tabela 1) sob mesma técnica supracitada, sendo possível notar ao hemograma anemia normocítica normocrômica e leucopenia. Através da bioquímica observou-se hipoproteinemia, diminuição da atividade das enzimas amilase, lipase e alanina aminotransferase (ALT). A função renal e a glicemia permaneceram nos padrões de normalidade. Sendo a mensuração da lipase e amilase, analisadas pelo método enzimático colorimétrico e substrato direto respectivamente. A glicemia foi mensurada com glicosímetro da marca Glucotrend (Boehringer Mannheim), mantendo-se nos parâmentros de normalidade. À ultrassonografia abdominal verificou-se fígado com dimensões preservadas, contornos regulares e lisos, ecogenicidade aumentada e ecotextura homogênea. Vasculatura pérvea com calibre preservado (Figura 4). Lobo pancreático direito aumentado com ecogenicidade mista e ecotextura heterogênea, apresentando áreas hipoecogênicas arredondadas, entremeadas por um parênquima predominantemente ecogênico. Veia pancreaticoduodenal com calibre aumentado e trajeto habitual. Tênue aumento de ecogenicidade da gordura peri-pancreática e presença de líquido livre abdominal (Figura 5).

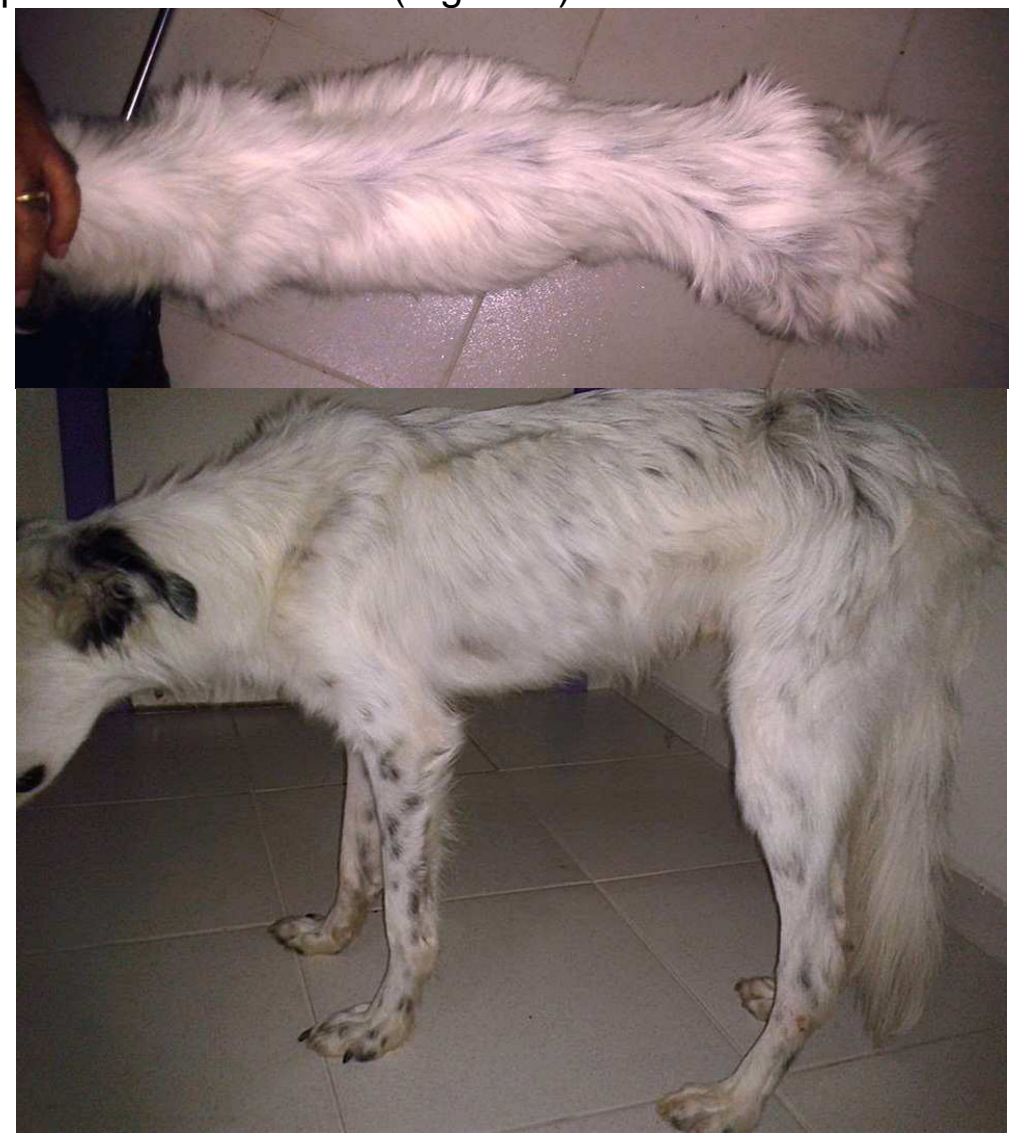

FIGURA 3: Cão, macho, Border Collie, escore corporal (1/9).

Fonte: Arquivo pessoal. 


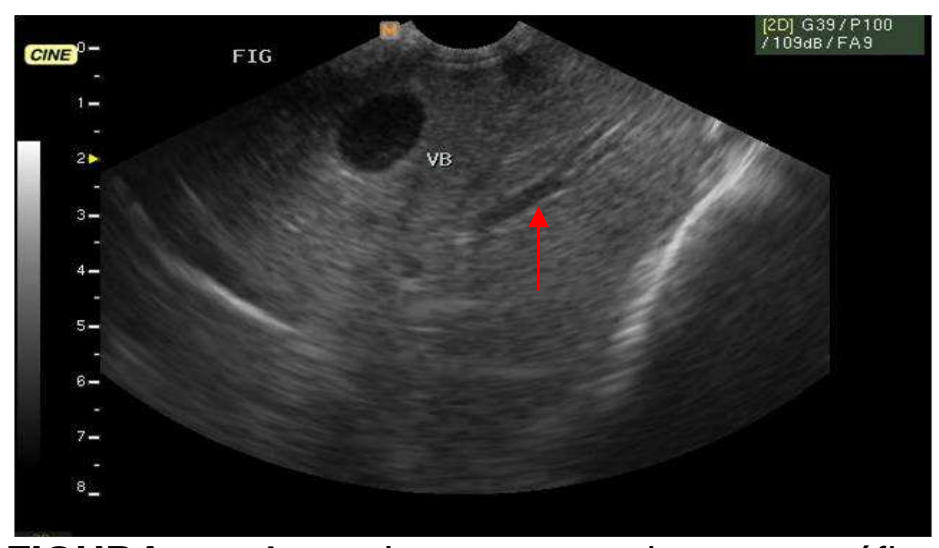

FIGURA 4: Imagem ultrassonográfica evidenciando veias hepáticas e alguns ramos portais (vasos com paredes mais ecogênicas) (seta vermelha). Fonte: Arquivo pessoal.

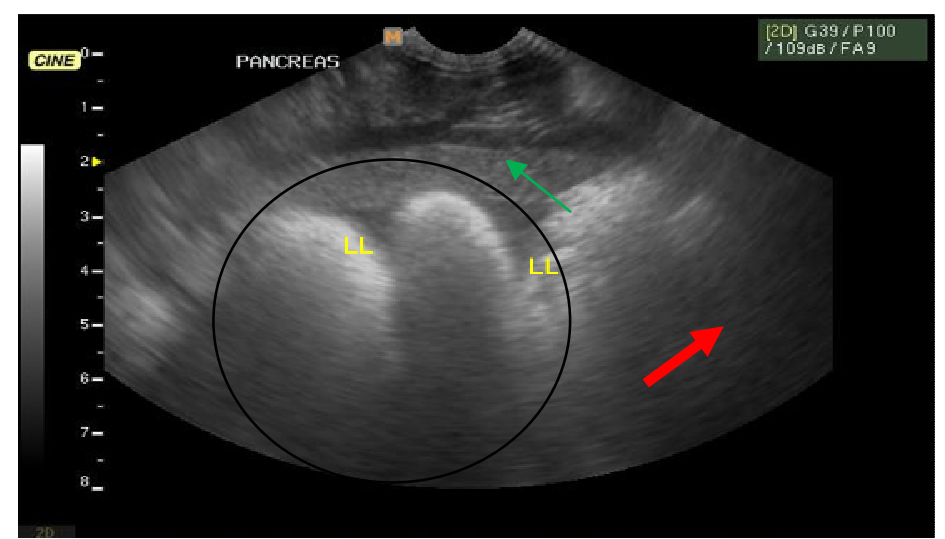

Figura 5: Imagem ultrassonográfica evidenciando veia pancreaticoduodenal congesta (seta verde). Lobo pancreático direito aumentado com ecogenicidade mista e ecotextura heterogênea, apresentando áreas hipoecogênicas arredondadas, entremeadas por um parênquima ecogênico (círculo). Tênue aumento de ecogenicidade da gordura peripancreática (seta vermelha). Fonte: Arquivo pessoal. 
TABELA 1: Resultado dos exames laboratoriais referentes aos dois casos relatados, assim como os valores de referência.

\begin{tabular}{|c|c|c|c|}
\hline & Caso 1 & Caso 2 & $\begin{array}{l}\text { Valores de } \\
\text { referência* }\end{array}$ \\
\hline Hemácias & $\begin{array}{c}3,46 \\
\text { milhões } / \mathrm{mm}^{3}\end{array}$ & $\begin{array}{c}2,65 \\
\text { milhões } / \mathrm{mm}^{3} \\
\end{array}$ & 6-8 milhões $/ \mathrm{mm}^{3 *}$ \\
\hline Hemoglobina & $8,8 \mathrm{~g} \%$ & $6,8 \mathrm{~g} \%$ & $14-18 \mathrm{~g} \%{ }^{*}$ \\
\hline Hematócrito & $25,1 \%$ & $18,4 \%$ & $40-53 \%{ }^{*}$ \\
\hline V.C.M & $72,5 \mathrm{fl}$ & $69,4 \mathrm{fl}$ & $65-\left.78 f\right|^{*}$ \\
\hline H.C.M & $25,4 p g$ & $25,6 p g$ & $21-26 p g^{*}$ \\
\hline C.H.C.M & $35 \%$ & $36,9 \%$ & $31-35 \%{ }^{*}$ \\
\hline Leucócitos Totais & $19300 / \mathrm{mm}^{3}$ & $4100 / \mathrm{mm}^{3}$ & $8-16 \mathrm{mil} / \mathrm{mm}^{3 *}$ \\
\hline Bastonetes & $7 \%$ & $1 \%$ & 0 a $3 \%^{*}$ \\
\hline Segmentados & $67 \%$ & $73 \%$ & $58-78 \%$ ** \\
\hline Linfócitos & $16 \%$ & $23 \%$ & 10 a $26 \%{ }^{*}$ \\
\hline Monócitos & $7 \%$ & $3 \%$ & 2 a $8 \% *$ \\
\hline Eosinófilos & $300 / \mathrm{mm}^{3}$ & $0 / \mathrm{mm}^{3}$ & 200 a $1200 / \mathrm{mm}^{3 V}$ \\
\hline Basófilos & $3 \%$ & 0 & 0 a $1 \%{ }^{*}$ \\
\hline Plaquetas & $483 \mathrm{mil} / \mathrm{mm}^{3}$ & $484 \mathrm{mil} / \mathrm{mm}^{3}$ & $\begin{array}{c}250 \text { a } 500 \\
\mathrm{mil} / \mathrm{mm}^{3 *}\end{array}$ \\
\hline Proteínas Totais & $4,5 \mathrm{~g} / \mathrm{dl}$ & $3,6 \mathrm{~g} / \mathrm{dl}$ & 5,3 a $8,1 \mathrm{~g} / \mathrm{dL}^{*}$ \\
\hline Amilase & - & $750 \mathrm{U} / \mathrm{L}$ & 300 a $1200 \mathrm{U} / \mathrm{L}^{*}$ \\
\hline Lipase & - & $10 \mathrm{U} / \mathrm{L}$ & 25 a 750 U/L* \\
\hline Albumina & - & $1,7 \mathrm{~g} / \mathrm{dL}$ & 2,3 a $3,8 \mathrm{~g} / \mathrm{dL}^{*}$ \\
\hline Globulinas & - & $1,9 \mathrm{~g} / \mathrm{dL}$ & 2,3 a 5,2 g/dL* \\
\hline FA & 1991UI/L & $65 \mathrm{UI} / \mathrm{L}$ & 0 a $89 \mathrm{UI} / \mathrm{L}^{*}$ \\
\hline ALT & $80 \mathrm{U} / \mathrm{L}$ & $238 \mathrm{U} / \mathrm{L}$ & 7 a 39U/L* \\
\hline Tempo de Protrombina & 8 segundos & - & $\begin{array}{l}4,07 \text { a } 9,67 \\
* * \text { segundos }\end{array}$ \\
\hline $\begin{array}{l}\text { Tempo de Tromboplastina } \\
\text { Parcial }\end{array}$ & $\begin{array}{c}12 \\
\text { segundos }\end{array}$ & - & $\begin{array}{c}11,9 \text { a } 18,3^{\star *} \\
\text { segundos }\end{array}$ \\
\hline Ureia & $63 \mathrm{mg} / \mathrm{dL}$ & - & 20 a $56 \mathrm{mg} / \mathrm{dL}^{*}$ \\
\hline Creatinina & $1,5 \mathrm{mg} / \mathrm{dL}$ & - & 0,5 a $1,5 \mathrm{mg} / \mathrm{dL}^{*}$ \\
\hline Bilirrubina Total & $2,17 \mathrm{mg} / \mathrm{dL}$ & - & 0,1 a $0,5 \mathrm{mg} / \mathrm{dL}^{*}$ \\
\hline Bilirrubina Direta & $0,2 \mathrm{mg} / \mathrm{dL}$ & - & 0,06 a $0,12 \mathrm{mg} / \mathrm{dL}^{*}$ \\
\hline Bilirrubina Indireta & 1,97 & - & 001 a $0,49 \mathrm{mg} / \mathrm{dL}^{*}$ \\
\hline Glicemia & $80 \mathrm{mg} / \mathrm{dL}$ & $90 \mathrm{mg} / \mathrm{dL}$ & $76-119 \mathrm{mg} / \mathrm{dL}^{*}$ \\
\hline
\end{tabular}

\section{DISCUSSÃO}

Cães jovens das raças Cocker Spaniel Inglês, Pastor Alemão e Collie apresentam predisposição à IPE (CARVALHO et al., 2010), corroborando assim com os presentes relatos, onde o primeiro animal relatado era Cocker Spaniel Inglês e o segundo Border Collie.

O quadro de desnutrição era evidente em ambos os animais, embora apresentassem polifagia, os alimentos ingeridos não estavam sendo absorvidos, sendo excretados nas fezes devido a IPE. Consequentemente estes apresentavam hipotrofia muscular em membros pélvicos, sobre região escapular, de costelas e em ENCICLOPÉDIA BIOSFERA, Centro Científico Conhecer - Goiânia, v.11 n.22; p. 84 2015 
músculo temporal, demonstrando baixo escore corporal (LAFLAMME, 1997; BALDWIN et al., 2010).

A glicemia dos dois caninos estava dentro dos padrões de normalidade demostrando que, embora o pâncreas exócrino estivesse comprometido, a sua função endócrina não foi afetada. Observação diferente da realizada por BRENNER et al. (2009) que descreveram quadro de Diabetes Mellito associado à IPE em dois cães.

Não existe um padrão hematológico pré-estabelecido para o quadro de desnutrição em cães, entretanto estudo realizado em cães subnutridos hospitalizados demonstrou que estes apresentavam valores reduzidos de proteínas totais e hemoglobina (BRUNETTO et al., 2010), assim como observado com os dois animais acompanhados no presente relato. Alterações clínicas como hipotricose, ressecamento do pelame, prostração e atrofia muscular são compatíveis com o quadro de hipoproteinemia ocasionada pela desnutrição observada nos dois casos (PAPINI et al., 2008).

Como nos estudos realizados por CHOWDHURY et al. (2007) e NAGATA et al. (2015) em humanos subnutridos, notou-se um prejuízo na função hepática, sugerindo dano aos hepatócitos ocasionado pelo quadro de desnutrição. Tais danos, provavelmente, ocorrem secundários ao aumento da captação de substâncias hepatotóxicas decorrentes da perda da integridade do intestino delgado causado pela IPE (WILLIAMS, 2008). Assim como no primeiro caso aqui apresentado, quadro de esteatose em ratos com hipoproteinemia também foi verificado por CASTRO et al. (2009).

As alterações pancreáticas observadas ao exame ultrassonográfico no segundo caso foram condizentes com o relatado por HECHT \& HENRY (2007) para pancreatite aguda (aumento e hipoecogenicidade) e crônica (ecogenicidade mista de parênquima e dilatação de dutos pancreáticos). Nos dois casos relatados a presença de alterações hepáticas encontradas na ultrassonografia em associação com as alterações nas enzimas hepáticas sugeriram um comprometimento hepático associado ao quadro de IPE. Concordando com FEENEY et al. (2008) que afirmam a importância do exame ultrassonográfico e os testes bioquímicos no diagnóstico de lesões hepáticas.

O aumento da ecogenicidade do parênquima hepático associado a uma ecotextura heterogênea indica um quadro de fibrose hepática (MAMPRIM, 1999), sendo necessária a realização da biopsia hepática para confirmação (FEENEY et al., 2008). A ultrassonografia realizada no primeiro caso foi essencial no direcionamento do clínico para a realização da biópsia hepática, na qual foi possível confirmar o comprometimento hepático com a presença de esteatose acentuada, fibrose e retenção de pigmento biliar secundárias à desnutrição.

Dados na literatura a respeito das alterações hematológicas e imaginológicas resultantes da IPE ainda são escassos e contraditórios, devido ao fato destas estarem correlacionadas à muitos outros processos patológicos e caracterizarem principalmente um quadro de desnutrição.

\section{CONCLUSÃO}

Os achados laboratoriais em animais com IPE podem ser controversos e inespecíficos não possibilitando excluir outras enfermidades. Exames imaginológicos e laboratoriais não definem o quadro de desnutrição, o qual é identificado por meio de exame clínico e com base no escore de condição corporal, mas são de grande auxílio, quando utilizados em conjunto, no diagnóstico de IPE. Uma vez sendo 
possível identificar e eliminar a causa primária ou quando os animais são suplementados com enzimas digestivas em doses suficientes a condição de normalidade pode ser restabelecida.

\section{REFERÊNCIAS}

BATCHELOR, D. J., NOBLE, P. J. M., CRIPPS, P. J., TAYLOR, R. H., MCLEAN, L., LEIBL, M. A., \& GERMAN, A. J. Breed associations for canine exocrine pancreatic insufficiency. Journal of Veterinary Internal Medicine, v.21, p.207-214, 2007.

BRENNER, K., HARKIN, K. R., ANDREWS, G. A., \& KENNEDY, G. Juvenile pancreatic atrophy in Greyhounds: 12 cases (1995-2000). Journal of Veterinary Internal Medicine, v.23, p.67-71, 2009.

BRUNETTO, M. A., GOMES, M. O., ANDRE, M. R., TESHIMA, E., GONÇALVES, K. N., PEREIRA, G. T., FERRAUDO, A. S. \& CARCIOFI, A. C. Effects of nutritional support on hospital outcome in dogs and cats. Journal of Veterinary Emergency and Critical Care, v.20, n.2, p.224-231, 2010.

CARVALHO, C. F., SILVA, E. B., \& SILVA, L. C. S. Insuficiência pancreática exócrina em um cão da raça Cocker Spaniel Inglês - Relato de caso. Ambiência Guarapuava (PR), v.6, n.3, p.523-527, 2010.

CASTRO, S .F. G. MIALICH, M. S; ANJOS, E. M.; ALMEIDA, L. P.; ARROYO, P. F.; PORTARI, G. V.; JORDÃO JUNIOR, A. A. Characterization of nonalcoholic fatty liver disease in rats for low protein diet induced, v.42, n.1, p.48-53, 2009. Dísponivel em: http://bases.bireme.br/cgiin/wxislind.exe/iah/online/?IsisScript=iah/iah.xis\&src=google \&base $=$ LILACS\&lang=p\&nextAction=Ink\&exprSearch=541557\&indexSearch=ID Data de Acesso 10/11/2015.

CHOWDHURY M.S.I..; RAHMAN.; HAQUE M..; NAHAR N.; TAHER, A., J. Serum Aspartate Aminotransferase (AST) and Alanine Aminotransferase (ALT) Levels in Different Grades of Protein Energy Malnutrition Journal of Bangladesh Society of Physiologist, v.2, p. 217-19, 2007.

COUTO, J. L. A., VIEIRA, R. C. D. S., BARBOSA, J. M., MACHADO, S. S., \& FERREIRA, H. D. S. Liver function abnormalities in undernourished and Schistosoma mansoni - infected mice. Revista da Sociedade Brasileira de Medicina Tropica, v.41, n.4, p.390-393, 2008.

FEENEY, D. A., ANDERSON, K. L., ZIEGLER, L. E., JESSEN, C. R., DAUBS, B. M., \& HARDY, R. M. Statistical relevance of ultrasonographic criteria in the assessment of diffuse liver disease in dogs and cats. American Journal of Veterinary Research, v.69, p.212-221, 2008.

GERMAN, A. J. Exocrine pancreatic insufficiency in the dog: Breed associations, nutritional considerations and long-term outcome. Topics in Companion Animal Medicine, v.27, p.104-108, 2012. 
HECHT, S.; HENRY, G. Sonographic evaluation of the normal and abnormal pancreas. Clinical Techniques in Small Animal Practice, v.22, n.3, p.115-121, 2007.

LAFLAMME, D. P. Development and Validation of a Body Condition Score System for Dogs. Canine Practice, v.22, p.10-15, 1997.

LOPES, S. T. D. A., EMANUELLI, M. P., SCHMIDT, C., RAISER, A. G., MAZZANTI, A., \& ALVES, A. S. Reference ranges of prothrombin time (PT) and activated partial thromboplastin time (aPTT) in dogs. Ciência Rural, v.35, n.2, p.381-384, 2005.

MAMPRIM, M. J. Doença hepática difusa em cães: estudo ultra-sonográfico comparativo com exames bioquímicos, biopsia e citologia aspirativa com agulha fina. Botucatu, 102p. Tese (Doutorado em Cirurgia Veterinária) - Faculdade de Medicina Veterinária e Zootecnia - UNESP- Campus de Botucatu, Universidade Estadual Paulista "Júlio de Mesquita Filho". 1999.

MARCATO, J. A. Pancreatite em cães. Trabalho de conclusão de curso (graduação), UFRGS, Porto Alegre, 2010.

MORGAN, J. A.; MOORE, L. E. A quick review of canine exocrine pancreatic insufficiency.Veterinary Medicine, v.104, n.9, p.427-434, 2009.

NAGATA, J. M., PARK, K. T., COLDITZ, K., \& GOLDEN, N. H. Associations of Elevated Liver Enzymes among Hospitalized Adolescents with Anorexia Nervosa. The Journal of Pediatrics, v.166, n.2, p.439-443, 2015.

NELSON, R. W.; COUTO, C. G. O pâncreas exócrino.In: Small animal internal medicine.4 ed. Rio de Janeiro: Elsevier, p. 596-600.2009.

PAPINI, S.D.J.P.; ECCO, R.; ARAUJO, M. R. ; CAIRES, C. E. T.; ALMEIDA W. B.. Atrofia do pâncreas exócrino em Pastor alemão. Clínica Veterinária, São Paulo, v.73, p.50- 54, 2008.

ROSENFELD, G. Etilenodiaminotetracético dissódica (EDTA) como anticoagulante para técnica hematológica. Vet. Clin., v.31, p.65-71, 1955.

STEINER, J. M. Exocrine Pancreatic Insufficiency in the Cat. Topics in Companion Animal Medicine, v.27, n.3, p.113-116, 2012.

WEISS, D. J.; WARDROP, J. K. (Ed.) Schalm's Veterinary Hematology. 6 ed. Ames-USA: Wiley-Blacwell Publication, 2010.1206p.

WESTERMARCK, E., SAARI, S. A. M., \& WIBERG, M. E. Heritability of exocrine pancreatic insufficiency in German shepherd dogs. Journal of Veterinary Internal Medicine, v.24, p.450-452, 2010.

WESTERMARCK, E.; WIBERG, M. Exocrine pancreatic insufficiency in the dog: Historical background, diagnosis and treatment. Topics in Companion Animal Medicine, v.27, p.96-103, 2012. 
WILLIAMS, D. A. Doença pancreática exócrina. IN: ETTINGER, S. J.; FELDMAN, E. C. Tratado de medicina interna veterinária: doenças do cão e do gato. 5 ed. Rio de Janeiro: Guanabara Koogan, p.1418-1441.2008. 